\title{
The Impact of the Sense of Coherence on the Problematic Internet Use among Secondary School Students
}

\author{
Joanna Skonieczna ${ }^{1 *}$, Adam Fronczak ${ }^{1}$, Aleksandra Kielan ${ }^{1}$, Anna Brytek-Matera $^{2}$ and Dominik Olejniczak ${ }^{1}$ \\ ${ }^{1}$ Department of Public Health, Faculty of Health Science, Medical University of Warsaw, Poland \\ ${ }^{2}$ Department of Psychology, SWPS University of Social Sciences and Humanities, Poland
}

"Corresponding author: Joanna Skonieczna, Department of Public Health, Faculty of Health Science, Medical University of Warsaw, Zielonki Wieś, Poland, Tel: +48519157076; E-mail: jskonieczna90@gmail.com

Received date: December 10, 2018; Accepted date: December 17, 2018; Published date: December 20, 2018

Copyright: @ 2018 Skonieczna J, et al. This is an open-access article distributed under the terms of the Creative Commons Attribution License, which permits unrestricted use, distribution, and reproduction in any medium, provided the original author and source are credited.

\section{Abstract}

Objective: The omnipresence and functionality of the Internet as well as its common use by the society influence the constantly growing number of research devoted to the problematic use of the Internet. Problematic Internet Use (PIU) is defined as an excessive engagement in the use of some Internet applications, creating psychological, social and health problems. The recent research have shown that adolescents using the Internet in a dysfunctional ways present several psychosocial problems. In the literature, there is no doubt that high sense of coherence (SOC) has a positive impact on human's health.
\end{abstract}

Methods: We used a simple random sample. The study group comprised of 1078 students of 9 randomly chosen secondary schools in Warsaw, Poland. All participants completed the Sense of Coherence Scale for Adolescents (SOC-11M), the version being adapted for Polish studies by Zwoliński; and the Internet Use Test which is a Polish adaptation of the Young's Internet Addiction Test by Poprawa.

Results: About $11.6 \%$ of students $(\mathrm{N}=125)$ showed a very high or high level of the PIU. We found a significant correlation between all dimensions of the PIU and the SOC. Secondary school students with lower level of the SOC showed the highest intensity of the PIU, while those with higher level of the SOC achieved the lowest results in the PIU.

Conclusions: There is a lack of studies focusing on the impact of SOC on the PIU. Results lead to conclusion that strengthening SOC would be a useful aspect of school-based health promotion programs focused on PUI prevention and reducing its negative health consequences. The psychosocial causes as well as the potential influences of SOC on the PIU should be studied in the future longitudinal research. In addition, the studies concerning the practical use of SOC, including intervention studies, would be valuable. The impact of sense of coherence on the Problematic Internet Use among secondary school students.

Keywords: Addictive behavior; Adolescents; Health behavior; Health promotion; Internet; Mental health; Sense of coherence

\section{Introduction}

The omnipresence and functionality of the Internet as well as its common use by the society influence the constantly growing number of research devoted to the problematic use of the Internet. The research has been initialized by Young [1] and Griffiths [2] in the middle of the 90s. A number of definitions, terms and methods of diagnosis concerning this health problem have been created since then. Many terms can be found in the literature, such as Internet addiction disorder [3,4], pathological Internet use [5], and compulsive Internet use [6], among others. The term Problematic Internet Use (PIU) has been adopted herein to define problems connected with the Internet addiction. According to Poprawa [7] this is the most neutral term. The description presents the problematic side, states the character of the problem and its durability. The PIU is defined as "excessive engagement in the use of some Internet applications (mainly connected with interactivity), creating psychological, social and health problems, having explicit characteristics of the addictive behavior" (p.
59). Poprawa lists the following symptoms of the PIU: difficulties with the control of activity in the Internet; compulsive-obsessive thinking; satisfaction loss and intensifying need; increasing damages and conflicts; neglecting other activities and relationships; addictive escape from stress; as well as defending the addiction [7].

Cash et al. [8] underline that the scope of research on the PIU has been developed very quickly, even without being officially recognized. The PIU has not been placed in the classification of the Diagnostic and Statistical Manual of Mental Disorders-5. The need for further research has been demonstrated by putting the "Internet Gaming Disorder" in the annex containing the proposed diagnostic categories [9]. In the International Statistical Classification of Diseases and Related Health Problems (ICD-11), gaming disorder (6C51) has been added to the section on disorders due to addictive behaviors. Currently, there is an ongoing debate on classification of the PIU-whether it should be classified as addiction (behavioral), impulse control disorder, or obsessive-compulsive disorder [8].

Adolescents are particularly exposed to undertaking risky behaviors connected with the PIU, which was shown by Critselis, among others [10]. The percentage of adolescents in the risk of PIU is constantly 
growing [11]. The Internet is more and more perceived by the adolescents as a mean for gaining information, entertainment and socialization, which is easily accessible. The excessive Internet use may cause psychological, social, educational and/or professional problems. Research shows that children and adolescents are significantly more exposed to negative effects of the Internet abuse than adults [12].

Adolescents constitute the group which commonly uses the Internet. According to Research and Academic Computer Network (NASK) results, around $93.4 \%$ of the investigated secondary and high school adolescents in Poland use the Internet at home many times a day (they are available online all the time). About $39.2 \%$ of respondents remain online during lessons at school. It is worth emphasizing that around $30 \%$ of adolescents stay online continuously, regardless of the place they are at that moment [13].

The European Network for Adolescent Addictive Behavior (EU NET ADB) study has shown that about $1.3 \%$ of Polish adolescents met the criteria of the Internet abuse. Individuals showing only some symptoms (e.g., saying "just a few more minutes" when on-line, staying on-line longer than you intended), and thus being in danger of abuse, comprise larger group. In Poland this group includes around $12.1 \%$ of adolescents [14].

Results of research conducted within the Program Safer Internet Plus framework have confirmed the relation between the PIU in adolescents group and poorer skills at school, smaller social activity and more serious psychosocial problems. Adolescents using the Internet on functional basis have shown better results on the school skills than teenagers showing the symptoms of dysfunctional use of the Internet [14]. Adolescents using the Internet in a dysfunctional way also have presented lower results on the scales connected with psychosocial problems, such as thought disorder, anxiety [15] and depression [16]. Cross-sectional studies also have showed the relation between the PIU and attention deficit hyperactivity disorder [17], obsessive-compulsive disorder and aggression [18]. Moreover, studies show correlation between Internet applications and stress, e.g., problematic Facebook use is positively correlated with signs of psychological distress, including anxiety and depression [19].

This research is based on theoretical Antonovsky's Salutogenic Model, which focuses on people's strengths and capacity for successful adaptation to life stressors, e.g. sense of coherence. Sense of Coherence (SOC) is defined as "a global orientation that expresses the extent to which one has a pervasive, enduring though dynamic feeling of confidence that: (1) the stimuli deriving from one's internal and external environments in the course of living are structured, predictable, and explicable (comprehensibility); (2) the resources are available to one to meet the demands posed by the stimuli (manageability); and (3) these demands are challenges, worthy of investment and engagement (meaningfulness)" [20]. SOC develops in the process of socialization during the whole life; nevertheless, childhood and adolescence demonstrate crucial importance. Repetitive experiences characterized by stability, harmony and one's participation in decision-making processes also have significant impact on SOC. It has been proved that high SOC is a health-promoting factor, thus it has a positive impact on human's health and functioning, and as a result, on the quality of life $[21,22]$.

During the past years, SOC have been well researched within the psychology and health science. SOC is an active protective factor also of adolescents' health. The systematic review revealed that adolescents' SOC is related to health in terms of quality of life, health behavior, mental health and family relationships [23], e.g. positively predicted quality of life over time in adolescents with Congenital Heart Disease (CHD) [24]. Health Behavior in School-aged Children (HBSC) survey showed that among adolescents a higher SOC was associated with better self-related health, lower frequency of somatic and psychological complaints and higher Quality of Life (QOL) and life satisfaction [25].

Although SOC has been studied in comparison with variety of health problems, evidence is limited regarding the influence of SOC on the PIU. Authors found only one research which analyzes SOC protective influence on the PIU [26], but it was published more than 10 years ago, when the access to Internet wasn't as much extended as these days.

SOC can be considerate as a resilience resource which helps adolescents to cope with stress and thereby may positively influence on choosing constructive ways to overcome problems and difficulties, instead of escaping into Internet applications. We hypothesized that strong sense of coherence among adolescents will be positively and significantly related to lower results in PIU test, which means more functional Internet activity. Thus, the aim of this study was to investigate the relationships between sense of coherence and PIU in secondary schools students in Warsaw.

\section{Materials and Methods}

\section{Participants and procedure}

The study surveyed a sample 1078 students of 9 randomly chosen secondary schools in Warsaw, Poland. The sampling frame was a list of secondary schools in Warsaw on the website of The Education Office in Warsaw. Total number of Warsaw schools, excluding special schools and schools for adults, was 30. Sample was created using sampling data analysis tool providing by Excel program. The Necessary Sample Size was calculated and ensured taking cognizance of refusal of participation of schools.

The application for giving permission for conducting the study together with the letter informing about the study aim and with the questionnaire was given to the principals and guidance counselors from every school qualified to the study. According to the school's Rules and Regulations, in some schools the consent of parents or legal guardians was required and obtained.

The respondents were informed about the aim of the study, anonymity, and their right to refuse participation as well as to not answer selected questions. Students completed questionnaires on their own during the lesson and under the supervision of the researcher. Part of respondents refused to perform the study or the questionnaires were excluded because they were clearly invalid (e.g. all responses always checked), (N=73). Time needed to fill in the questionnaires was around 25 minutes.

Nearly $43.7 \%$ (468) of respondents were boys, and about $56.3 \%$ (603)-girls (gender was not identified for seven of the participants). Respondents were born in the years 1998-2003. Study group comprised of 390 students (36.2\%) of the 1st grade of secondary school (about 13 years old), 384 students (35.6\%) of the 2nd grade (about 14 years old), and 304 students $(28.2 \%)$ of the 3 rd grade (about 15 years old). 
Citation: Skonieczna J, Fronczak A, Kielan A, Brytek-Matera A, Olejniczak D (2018) The Impact of the Sense of Coherence on the Problematic Internet Use among Secondary School Students. J Health Educ Res Dev 6: 290. doi:10.4172/2380-5439.1000290

Page 3 of 6

\section{Measures}

The research technique was random survey. The research tool was questionnaire in the paper or on-line form. The questionnaire was subjected to the pilot study. The questionnaire comprised of sociodemographic characteristics, including year of birth, age, gender. We used two questionnaires:

The Sense of Coherence for Adolescents scales SOC-11M for measuring the SOC. The original tool for measuring the SOC in adults was created by Poprawa [27]. We used the Polish adaptation by Zwoliński intended for adolescents [20]. Cronbach's a for the SOC scale in the present study was 0.886 .

The Polish adaptation of the Young's Internet Adiction Test which measures the PIU which is described by 7 categories of symptoms: difficulties with self-control, obsessive thinking and mood changes, satisfaction loss, increasing damages and conflicts, neglecting other activities and relationships, escaping from stress to the Internet, and defending the addiction [28]. The Cronbach's alpha coefficient was 0.922 [7].

\section{Statistical analysis}

All statistical analyses were conducted with the use of the IBM program SPSS Statistics, version 23. The adopted threshold of significance is the traditional level of $\mathrm{p}$ value $<0.05$.

\section{Ethics}

The study procedures were carried out in accordance with the Declaration of Helsinki. The Institutional Review Board of the Medical University of Warsaw approved the study (AKBE/99/15). Participants provided informed consent and voluntarily participated following the assurance of confidentiality and anonymity.

\section{Results}

Respondents declared their health condition. More than half of respondents $(54.7 \%, 590)$ declared good health condition. Every third $(29 \%, 313)$ perfect condition. About 3.4\% (37) declared that their health condition was poor, $12.8 \%$ (138) declared it was tolerable. In order to assess whether there is a relationship between the levels of PIU and the self-assessment of health status, a correlation analysis was performed with the Kendall tau-b coefficient. Based on the results obtained, it can be concluded that the state of health is statistically significantly related to all dimensions of PIU. These dependencies, however, are quite weak $(\mathrm{p}<0.001$, tau $=-0.145)$.

The study variables' means and standard deviations are illustrated in Table 1.

\begin{tabular}{|l|l|l|l|l|l|}
\hline & M & Me & SD & K-S & p \\
\hline Sense of Coherence Scale & $\begin{array}{l}37.2 \\
7\end{array}$ & $\begin{array}{l}38.0 \\
0\end{array}$ & 8.71 & $\begin{array}{l}0.0 \\
5\end{array}$ & $\begin{array}{l}<0.00 \\
1\end{array}$ \\
\hline Problems with self-control & 5.05 & 4.00 & 2.81 & $\begin{array}{l}0.2 \\
3\end{array}$ & $\begin{array}{l}<0.00 \\
1\end{array}$ \\
\hline Obsessive thinking and mood changes & 7.67 & 6.00 & 3.75 & $\begin{array}{l}0.2 \\
4\end{array}$ & $\begin{array}{l}<0.00 \\
1\end{array}$ \\
\hline Satisfaction loss & 4.32 & 3.00 & 2.23 & $\begin{array}{l}0.3 \\
0\end{array}$ & $\begin{array}{l}<0.00 \\
1\end{array}$ \\
\hline Increasing damages and conflicts & 5.96 & 5.00 & 2.77 & $\begin{array}{l}0.1 \\
6\end{array}$ & $\begin{array}{l}<0.00 \\
1\end{array}$ \\
\hline $\begin{array}{l}\text { Neglecting other activities } \\
\text { relationships }\end{array}$ & 4.78 & 4.00 & 2.39 & $\begin{array}{l}0.2 \\
5\end{array}$ & $\begin{array}{l}<0.00 \\
1\end{array}$ \\
\hline Escape from stress to the Internet & 6.84 & 6.00 & 3.59 & $\begin{array}{l}0.1 \\
7\end{array}$ & $\begin{array}{l}<0.00 \\
1\end{array}$ \\
\hline Psychological defense of an addiction & 4.90 & 4.00 & 2.82 & $\begin{array}{l}0.2 \\
6\end{array}$ & $\begin{array}{l}<0.00 \\
1\end{array}$ \\
\hline TOTAL_PUI & 39.5 & 35.0 & 15.8 & $\begin{array}{l}0.1 \\
5\end{array}$ & $\begin{array}{l}<0.00 \\
1\end{array}$ \\
\hline
\end{tabular}

Table 1: Means and Standard Deviations of the PUI total score and subscales and SOC.

The general level of PIU was assessed in the tested group, based on the Polish adaptation of the Internet Addiction Test. The analyses showed that $0.7 \%$ (8) of tested students shows a very high level of PIU, and $10.9 \%$ (117) of students-a high level of PIU. The moderate and low level was achieved by almost $60.9 \%$ (656) and $27.6 \%$ (297) students respectively.

The level of SOC was assessed based on the SOC-11. The study showed that about $33.2 \%$ (358) of tested adolescents show a high level of SOC, $43.5 \%$ (468)-moderate level of SOC, and 23.3\% (251)-low level of SOC.

Table 2 shows the level of the PIU with its particular dimensions and SOC in total and in gender breakdown. A backward stepwise approach identified male sex (95\% Confidence Interval [CI], 0.06-0.17; $\mathrm{P}=0.000)$ as independent risk factors of PIU, and female sex $(95 \% \mathrm{CI}$, 0.06-0.17; $\mathrm{P}=0.000)$, attending the school class 3 (95\% CI,-0,19-(-0.06); $\mathrm{P}=0.000)$ and high SOC (95\% CI,-0.39-(-0.28); $\mathrm{P}=0.000)$, as independent protective factors of PIU.

\begin{tabular}{|c|c|c|c|c|c|c|c|}
\hline & \multicolumn{2}{|c|}{ Girls } & \multicolumn{2}{|c|}{ Boys } & \multirow{3}{*}{$\mathrm{t}$} & \multirow{3}{*}{$\mathbf{p}$} & \multirow{3}{*}{$\begin{array}{l}\text { Cohen's d }(95 \% \\
\text { Cl) }\end{array}$} \\
\hline & \multicolumn{2}{|c|}{$(\mathrm{N}=603)$} & \multicolumn{2}{|c|}{$(\mathrm{N}=468)$} & & & \\
\hline & $\mathbf{M}$ & SD & M & SD & & & \\
\hline Problems with self-control & 2.1 & 2.83 & 2 & 2.72 & 0.597 & 0.55 & - \\
\hline $\begin{array}{l}\text { Obsessive thinking and mood } \\
\text { changes }\end{array}$ & 2.6 & 3.63 & 2.7 & 3.75 & -0.782 & 0.434 & - \\
\hline Satisfaction loss & 1.2 & 2.16 & 1.5 & 2.21 & -2.2 & 0.028 & $0.14(0.02-0.26)$ \\
\hline
\end{tabular}


Citation: Skonieczna J, Fronczak A, Kielan A, Brytek-Matera A, Olejniczak D (2018) The Impact of the Sense of Coherence on the Problematic Internet Use among Secondary School Students. J Health Educ Res Dev 6: 290. doi:10.4172/2380-5439.1000290

Page 4 of 6

\begin{tabular}{|l|l|l|l|l|l|l|l|}
\hline $\begin{array}{l}\text { Increasing damages and } \\
\text { conflicts }\end{array}$ & 2.9 & 2.9 & 3 & 2.55 & -0.434 & 0.664 & - \\
\hline $\begin{array}{l}\text { Neglecting other activities and } \\
\text { relationships }\end{array}$ & 1.6 & 2.25 & 1.9 & 2.49 & -2.047 & 0.041 & $0.13(0.01-0.25)$ \\
\hline $\begin{array}{l}\text { Escape from stress to the } \\
\text { Internet }\end{array}$ & 3.6 & 3.5 & 4.2 & 3.62 & -2.701 & 0.007 & $0.17(0.05-0.29)$ \\
\hline $\begin{array}{l}\text { Psychological defense of an } \\
\text { addiction }\end{array}$ & 1.7 & 2.6 & 2.1 & 3.02 & -2.564 & 0.01 & $0.14(0.02-0.26)$ \\
\hline TOTAL_PIU & 15.6 & 15.56 & 17.4 & 15.61 & -1.848 & 0.065 & - \\
\hline TOTAL_SOC-11 & 35.8 & 8.79 & 39.2 & 8.06 & -6.579 & 0 & $0.40(0.28-0.52)$ \\
\hline
\end{tabular}

Table 2: The level of the PIU with its particular dimensions and SOC in total and in gender breakdown (N=1078).

The possible association between the intensification of the SOC and the level of the PIU among the secondary school students have been verified. The results prove that there are statistically significant correlations between all dimensions of PIU and the SOC. These correlations are mostly weak to moderate (obsessive thinking, PIU), and their negative values demonstrate that the higher the SOC of subjects, the lower their PIU. These results are summarized in the Table 3.

\begin{tabular}{|c|c|c|c|c|c|c|c|c|}
\hline & \multicolumn{3}{|l|}{ Girls } & \multicolumn{3}{|l|}{ Boys } & \multirow{3}{*}{$z$} & \multirow{3}{*}{$\mathbf{p}$} \\
\hline & \multicolumn{3}{|c|}{$(\mathrm{N}=603)$} & \multicolumn{3}{|c|}{$(N=468)$} & & \\
\hline & $\mathbf{r}$ & $\mathbf{t}$ & $\mathbf{p}$ & $\mathbf{r}$ & $\mathbf{t}$ & $\mathbf{p}$ & & \\
\hline Problems with self-control & -0.29 & -7.548 & 0 & -0.29 & -6.48 & 0 & 0 & 1 \\
\hline $\begin{array}{l}\text { Obsessive thinking and } \\
\text { mood changes }\end{array}$ & -0.3 & -7.6 & 0 & -0.31 & -6.945 & 0 & 0.18 & 0.857 \\
\hline Satisfaction loss & -0.27 & -6.995 & 0 & -0.29 & -6.562 & 0 & 0.35 & 0.726 \\
\hline $\begin{array}{l}\text { Increasing damages and } \\
\text { conflicts }\end{array}$ & -0.31 & -8.103 & 0 & -0.25 & -5.643 & 0 & -1.05 & 0.294 \\
\hline $\begin{array}{l}\text { Neglecting other activities } \\
\text { and relationships }\end{array}$ & -0.31 & -8.056 & 0 & -0.26 & -5.91 & 0 & -0.88 & 0.379 \\
\hline $\begin{array}{l}\text { Escape from stress to the } \\
\text { Internet }\end{array}$ & -0.34 & -8.836 & 0 & -0.23 & -5.077 & 0 & -1.94 & 0.052 \\
\hline $\begin{array}{l}\text { Psychological defence of } \\
\text { an addiction }\end{array}$ & -0.23 & -5.787 & 0 & -0.27 & -5.978 & 0 & 0.69 & 0.49 \\
\hline TOTAL_PUI & -0.38 & -10.056 & 0 & -0.35 & -8.14 & 0 & -0.56 & 0.576 \\
\hline
\end{tabular}

Table 3: Correlations between the SOC and PIU with its particular dimensions.

\section{Discussion}

PIU constitutes a relatively new public health problem. Authors observed a need to analyze a problem in health promotion perspective, and to investigate if SOC-one of the most important factors in health promotion-influence on PIU.

In the authors' current study, it was indicated that among the 1098 secondary schools students, about $0.7 \%$ of adolescents showed a very high level of PIU, and $10.9 \%$ of them-a high level of PIU. This finding is consistent with that reported by Poprawa [7], who estimated that the prevalence of PUI to be $2 \%$ in the Polish adolescences at the age of 1519 years, and nearly $13 \%$ of them were at risk of PUI. In the study by Länsimies et al. conducted within the framework of research project
EU NET ADB, nearly $1.3 \%$ of respondents meet the criteria of Internet Addictive Behavior (IAB), and $12 \%$ is at risk of IAB [29].

The above-mentioned studies included different age structures of adolescents and made use of different tools. Nevertheless, it can be observed that the percentage of persons showing PIU and persons at risk of PIU remains at the level of a dozen or so percent. It means that there is a need to identify the factors protecting an individual and to implement solutions concerning health promotion in this scope.

Numerous studies confirm the impact of SOC on health [30], and on the quality of life [21]. The statistically significant relations between all dimensions of PIU and the SOC is confirmed by the author's own study. Individuals with the low SOC showed the highest intensity of 
Page 5 of 6

PIU, while those with high SOC achieved the lowest results in this scope, which was statistically significant.

The revision of literature was conducted and not numerous studies concerning the correlation between PIU and SOC were found. PIU is strongly related to stress in life and lack of SOC, which was showed by the study conducted by Poprawa and Dulewicz [30] in the group of 14,912 Internet users at the age of 9-65 years. It was confirmed that the lower the level of SOC was, especially its component which was the sense of resourcefulness, the stronger PIU was. Poprawa and Dulewicz [30] divided the respondents into three groups, based on the PIU level: unproblematic, risk, problematic. Statistically significant differences in terms of SOC level were observed, which achieved the following levels, respectively: $122.67,110.01$, and 102.83 .

The study conducted on individuals addicted to the Internet showed more pathological results in comparison to the control group of healthy people, both in the Beck Depression Inventory and in the Sense of Coherence Scale [32].

In the systematic review performed by Huang et al. [33] it was stated that the higher SOC was related with better Health Related Quality of Life (HRQoL). What is more, also strong correlation between SOC and social functioning was confirmed (correlation ratio 0.62-0.64), which is the ability of a person to interact easily and successfully with other people [33]. Social functioning influences quality of life, for example in the group of patients with depression the higher intensity of depression symptoms was observed in patients with lower level of personality functioning [34].

Neglecting other activities and relationships is recognized as PIU symptoms-the present study showed that SOC correlates with this variable moderately.

Adolescents showing PIU or being at risk of PIU experience anxiety and depression more often, which was confirmed by Lee and Stapinski [15] and Sasmaz et al. [16]? Reverse correlation was found between depression and anxiety, for example in a group of Norwegian teenagers at the age of $13-19$ years [35,36].

Our study showed that in both male and female groups, differ statistically significantly in terms of all dimensions of the PIU, however, the strength of these effects was slightly weak in male group.

Low SOC is more frequent in female students and is connected with the feeling of downcast, dissatisfaction with life, and psychosomatic discomfort [37]. The study conducted on the groups of adolescents by Moksnes et al. [36,37] showed that girls achieved higher results in terms of anxiety and depression when compared to boys. At the same time, they achieved lower results in SOC, and the effect of gender impact on SOC was stronger in their case. The above results suggest that girls make up the group where lower SOC is more frequent, and as a result, they are more exposed to PIU and its' effects on health.

Antonovsky [20] assumed that the SOC would be amplify from early socialization experiences during childhood and adolescence and maintained in adulthood [20]. Research shows that social support, for example support in school (from teachers, classmates) and family environment (from parents), and is associated with a stronger SOC in school students. Health promotion interventions providing for teachers, parents and school students, aimed to strengthen this aspect of mental health would be beneficial to reduce PUI prevalence and its negative health consequences.

\section{Conclusions}

The present work extends knowledge on PIU, directing our attention to the potential protective effect of a strong SOC. There are not many studies concerning the impact of SOC on PIU available in the Polish or English language.

This study is limited by the cross-sectional design. It does not acknowledge drawing conclusions about causal relationships between PIU and SOC. This research gives basis for further development of a topic. The results may lead to initiate additional longitudinal study in order to assess the proximate causes and to study the potential influences of SOC on PIU.

Results lead to conclusion that strengthening SOC would be a useful aspect of school-based health promotion programs focused on PUI prevention and reducing its negative health consequences. The studies concerning the practical use of SOC, including intervention studies, would be valuable.

\section{Author Disclosure Statement}

\section{Source of funding}

The work was carried out as part of the Research project implemented in 2016, financed from the statutory subsidy obtained by the Faculty of Health Sciences of the Medical University of Warsaw. No competing financial interests exist.

\section{References}

1. Young KS (1996) Psychology of computer use: XL. Addictive use of the Internet: a case that breaks the stereotype. Psychol Rep 79: 899-902.

2. Griffiths MD (1996) Internet "addiction": an issue for clinical psychology?. Clinical Psychology Forum 97: 32-36.

3. Young KS (1998) Internet addiction: the emergence of a new clinical disorder. Cyberpsychol Behav 1: 237-244.

4. Hsu WY, Chanz SM, Chiu NY, Lin SS, Tseng YH (2015) Examining the Application of the DC-IA-A Diagnostic Criteria for Internet Addiction Disorder in At-Risk College Students. Psychopathology 48: 408-416.

5. Durkee T, Carli V, Floderus B (2016) Pathological Internet Use and RiskBehaviors among European Adolescents. Int J Environ Res Public Health 13: 294.

6. Ciarrochi J, Parker P, Sahdra B (2016) The development of compulsive internet use and mental health: A four-year study of adolescence. Dev Psychol 52: 272-283.

7. Poprawa R (2012) The Problematic Internet Use Symptoms and diagnostic method. The study with teenager's sample. Psychology of Quality of Life 11: 57-82.

8. Cash H, Rae CD, Steel AH, Winkler A (2012) Internet Addiction: A Brief Summary of Research and Practice. Curr Psychiatry Rev 8: 292-298.

9. Substance-Related and Addictive Disorders. Diagnostic and Statistical Manual of Mental Disorders (DSM-5). American Psychiatric Association. www.dsm5.org, date of access: 11 June 2017.

10. Critselis E, Janikian M, Paleomilitou N (2014) Predictive factors and psychosocial effects of Internet addictive behaviors in Cypriot adolescents. Int J Adolesc Med Health 26: 369-375.

11. Pawłowska B, Potembska E (2011) Symptoms of the risk of Internet addiction and symptoms of Internet addiction measured using Pawłowska and Potembska's Internet Addiction Assessment Questionnaire in Polish young people aged 13 to 24 years. Curr Probl Psychiatry 12: 439-442. 
Citation: Skonieczna J, Fronczak A, Kielan A, Brytek-Matera A, Olejniczak D (2018) The Impact of the Sense of Coherence on the Problematic Internet Use among Secondary School Students. J Health Educ Res Dev 6: 290. doi:10.4172/2380-5439.1000290

Page 6 of 6

12. Kamal NN, Mosallem FA (2013) Determinants of problematic internet use among el-minia high school students, Egypt. Int J Prev Med 4 1429-1437.

13. NASK Research Institute (2016) Adolescents 3.0. Selected results of the nationwide study of students in Polish schools.

14. Makaruk K, Wójcik S (2012) EU NET ADB Consortium. EU NET ADB The study on overusing the Internet by the adolescents in Poland. Nobody's Children Foundation.

15. Lee BW, Stapinski LA (2012) Seeking safety on the internet: relationship between social anxiety and problematic internet use. J Anxiety Disord 26:197-205.

16. Sasmaz T, Oner S, Kurt AO (2014) Prevalence and risk factors of Internet addiction in high school students. Eur J Pub Health 24: 15-20.

17. Gundogar A, Bakim B, Ozer OA, Karamustafalioglu O (2012) The association between internet addiction, depression and ADHD among high school students. Eur Psychiatry 27: 1.

18. Cecilia MR, Mazza M, Cenciarelli S, Grassi M, Cofini V (2013) The relationship between compulsive behaviour and internet addiction. Styles of Commun 5: 24-31.

19. Marino C, Gini G, Vieno A, Spada MM (2018) The associations between problematic Facebook use, psychological distress and well-being among adolescents and young adults: A systematic review and meta-analysis. Journal of Affective Disorders 226: 274-281.

20. Antonovsky A (1987) Unravelling the mystery of health: How people manage stress and stay well. San Francisco: Jossey-Bass.

21. Eriksson M, Lindström B (2007) Antonovsky's sense of coherence scale and its relation with quality of life: a systematic review. J Epidemiol Community Health 61: 938-944.

22. García-Moya I, Rivera F, Moreno C, Lindström B, Jiménez-Iglesias A (2012) Analysis of the importance of family in the development of sense of coherence during adolescence. Scand J Public Health 40: 333-339.

23. Länsimies H, Pietilä AM, Hietasola-Husu S, Kangasniemi M (2017) A systematic review of adolescents' sense of coherence and health. Scand Caring Sci 31: 651-661.

24. Luyckx L, Missotten L, Goossens E, Moons P (2012) Individual and contextual determinants of quality of life in adolescents with congenital heart disease. J Adolesc Health 51: 122-128.
25. Garcia-Moya I, Moreno C, Rivera F (2013) Sense of coherence and biopsychosocial health in Spanish adolescents. Span J Psychol 16: 1-10.

26. Zwoliński M, Jelonkiewicz I, Kosińska-Dec K (2011) The scale of the sense of coherence for young people and its psychometric properties. The Art of Treatment 7: 31-35.

27. Poprawa R (2011) Test of problematic use of the Internet. Adaptation and psychometric evaluation. Internet Addiction. K. Young. Psychological Survey 54: 193-216.

28. Tsitsika A, Janikian M, Schoenmakers TM (2014) Internet Addictive Behavior in Adolescence: A Cross-Sectional Study in Seven European Countries. Cyberpsychol Behav Soc Netw 17: 528-535.

29. Poprawa R, Dulewicz D (2006) Stress, Sense of Coherence and Problematic Internet Use. In: Mesjasz J, Czapiga A, eds. Psychopathologies of Modern Society. Łódź, The Academy of Humanities and Economics in Lodz Publishing House, pp: 109-129.

30. Te Wildt BT, Putzig I, Zedler M, Ohlmeier MD (2007) Internet dependency as a symptom of depressive mood disorders. Psychiatr Prax 34: S318-322.

31. Huang IC, Lee JL, Ketheeswaran P, Jones CM, Revicki DA, et al. (2017) Does personality affect health-related quality of life? A systematic review. PLoS One, p: 12

32. Crempien C, Grez M, Valdés C, López MJ, de la Parra G, et al. (2017) Role of Personality Functioning in the Quality of Life of Patients with Depression. J Nerv Ment Dis, p: 27.

33. Moksnes UK, Espnes GA (2017) Stress, sense of coherence and subjective health in adolescents aged 13-18 years. Scand J Public Health 45: 397-403.

34. Moksnes UK, Espnes GA, Lillefjell M (2012) Sense of coherence and emotional health in adolescents. J Adolesc 35: 433-441.

35. Myrin B, Lagerström M (2008) Sense of coherence and psychosocial factors among adolescents. Acta Paediatr 97: 805-811.

36. Garc'1a-Moya I, Rivera F, Moreno C (2013) School context and health in adolescence: the role of sense of coherence. Scand J Psychol8 54: 243-249.

37. Natvig GK, Hanestad BR, Samdal O (2006) The role of the student: salutogenic or pathogenic?. Int J Nurs Pract 12: 280-287. 